\title{
Polymorphism Located in the Upstream Region of the RPS19 Gene (rs2305809) Is Associated With Cervical Cancer: A Case-control Study
}

SHORT

COMMUNICATION

\section{Thaís da Rocha Boeira', Janaina Coser ${ }^{2,3}$, Jonas Michel Wolf', Bruna Klahr Manggini Cardinal ${ }^{2}$, Ivana Grivicich ${ }^{1}$, Daniel Simon', Vagner Ricardo Lunge ${ }^{1}$}

${ }^{1}$ Graduate Program in Cellular and Molecular Biology Applied to Health, Lutheran University of Brazil (ULBRA), Canoas, ${ }^{2}$ Biomedicine Course, University of Cruz Alta (UNICRUZ), Cruz Alta, ${ }^{3}$ Graduate Program in Integral Health Care, University of Cruz Alta/Regional University of the Northwestern Rio Grande do Sul state (UNICRUZ/UNIJUÍ), Cruz Alta/ljuí, Brazil

Cervical cancer (CC) is caused by persistent human papillomavirus (HPV) infection and affects women worldwide. The progression of an HPV persistent infection to CC is influenced by genetic factors. Three single nucleotide polymorphisms (SNPS) in TP53, NQ01 and RPS19 genes (rs1042522, rs1800566, rs2305809, respectively) were previously associated with CC in European and North American populations. The present case-control study aimed to investigate the association of the SNPs rs1042522, rs 1800566, and rs2305809 with CC in an admixed population in southern Brazil. A total of 435 women (106 CC patients and 329 controls) were recruited for this study. All women were interviewed and underwent clinical sampling. SNPs rs1042522 and rs1800566 were evaluated by PCR-RFLP. SNP rs2305809 was determined by real-time PCR. The crude and adjusted ORs with $95 \% \mathrm{Cl}$ were estimated. The recessive genetic model (C/C $+C / T)$ for rs2305809 was more frequent in the control group (79.9\%) compared to the cases (69.8\%), being associated with CC protection (adjusted $\mathrm{OR}=0.49 ; 95 \% \mathrm{Cl}: 0.27-0.90$ ). However, the other polymorphisms evaluated did not present significant differences between cases and controls. This study detected a protective association for the recessive genetic model in rs 2305809 . These results suggest a potential role of the RPS19 gene in CC.

(J Cancer Prev 2018;23:147-152)

Key Words: Cervical cancer, Single nucleotide polymorphisms, Case-control study

\section{INTRODUCTION}

Cervical cancer $(\mathrm{CC})$ is the fourth most common cancer in women, with approximately 528,000 new cases in the world each year. ${ }^{1}$ In 2016, 16,340 new cases of CC were reported in Brazil. It is one of the top five most common cancer types in all states of the country. ${ }^{2}$ Human papillomavirus (HPV) persistence is a key factor in the development of $\mathrm{CC}$, inducing carcinogenesis by the integration of the whole genome into the cell host chromosome, transformation of the cervical cells and appearance of intraepithelial lesions that progress to $\mathrm{CC} .{ }^{3}$ However, most HPV-infected women do not progress to $\mathrm{CC}$, suggesting that other factors are related to this outcome. Socio-demographic (e.g., income, educational level, age, and multiparity) and behavioral (e.g., age at first intercourse, number of sexual partners) factors were already demonstrated to have a direct relationship to HPV exposure and persistence in the uterine cervix and progression to precancerous lesions. ${ }^{3}$ In addition, human genetic factors have also a pivotal influence in the development of $\mathrm{CC}^{4.5}$ Several single nucleotide polymorphisms (SNPs) of the human genome have been associated with CC in the last years. ${ }^{4.5}$ These SNPs are present in genes of different cell pathways, such as tumor suppression, inflammation, apoptosis and cell cycle regulation, DNA repair, cell migration, cell signaling and viral entry into the cell. ${ }^{4.5}$

Received July 17, 2018, Revised September 21, 2018, Accepted September 21, 2018

Correspondence to: Jonas Michel Wolf

Graduate Program in Cellular and Molecular Biology Applied to Health, Lutheran University of Brazil (ULBRA), Av. Farroupilha, 8001 - São José, Canoas - RS, 96923-101, Brazil

Tel: +55-51-34774000 (ext. 2433), Fax: +55-51-34774000 (ext. 2433), E-mail: jonasmwolf@gmail.com, ORCID: Jonas Michel Wolf, https://orcid.org/0000-0001-7577-464X

Copyright (C) 2018 Korean Society of Cancer Prevention

(c) This is an Open Access article distributed under the terms of the Creative Commons Attribution Non-Commercial License (http://creativecommons.org/licenses/by-nc/4.0) which permits unrestricted non-commercial use, distribution, and reproduction in any medium, provided the original work is properly cited. 
The TP53, NQO1, and RPS19genes are related with DNA repair mechanism and cell general function (e.g., metabolism, antioxidant activities, ribosomal structure). ${ }^{48}$ Specifically, the gene coding for the human tumor protein $\mathrm{p} 53$ is one of the most investigated in recent association studies. ${ }^{5}$ The SNP rs1042522, which causes a nucleotide modification $\mathrm{G}>\mathrm{C}$ with a consequent amino acid change in p53 (Arg72Pro), was reported to be associated with $\mathrm{CC}^{5}$ However conflicting results have been observed in different populations and both alleles have been associated with the risk for $\mathrm{CC} .{ }^{5.6}$ In addition, NAD (P) H: quinone oxidoreductase-1 gene (NQOI) has been also a preferential target of many genetic association studies since it codes an enzyme related to the cellular response to oxidative stress. The SNP rs1800566 causes a modification $\mathrm{C}>\mathrm{T}$ (in the position 609 of NQO1 gene) and a consequent amino acid change Pro187Ser in NQO-1 protein, resulting in reduced enzymatic activity and predisposition of CC in women with HPV infection. ${ }^{6}$ Further, RPS19 codes for a 40S subunit ribosomal protein (S19E family) and probably has an extra-ribosomal function in cell differentiation and proliferation. Two previous studies demonstrated an association between an SNP located in the upstream region of the RPS19 gene (rs2305809) and the risk of CC in Central American and African women. ${ }^{7.8}$

Few studies investigated the association of SNPs with CC in South America populations. Recently, we investigated some other SNPs previously associated to CC in genes related to immune response (IRF3), cell cycle (FANCA) and cell enzymes (DUT, FLJ35220, OAS3, and SULF1). ${ }^{7}$ However, we not found any association in an admixed population in southern Brazil. ${ }^{9}$ The present study evaluated the frequencies of other three SNPs (rs1042522 in TP53, rs1800566 in NQO1, and rs2305809 in RPS19) as well as the association of the respective alleles and genotypes with CC in the same admixed population in southern Brazil.

\section{MATERIALS AND METHODS}

\section{Study design and population}

The CC patients $(n=106)$ were recruited at the Center of High Complexity in Oncology (Centro de Assistência de Alta Complexidade em Oncologia) from 2012 to 2014. This center is located in the city of Ijui and treats cancer in women from the Northwest and Center regions of Rio Grande do Sul, the southernmost Brazilian state. These women had a medical history of HPV infection, presented CC diagnosis (squamous cell carcinoma or adenocarcinoma) and were receiving cancer treatment (chemo-, radio, and/or brachytherapy) when they were invited to participate of the study. The control group ( $n=329$ ) was selected by age-matched sampling from two previous cross-sectional studies conducted in the same region in the Rio Grande do Sul state. ${ }^{10,11}$ All these women presented normal cervical cytology at the moment of the recruitment. Sociodemographic and behavioral information was obtained through a questionnaire administered to all women. In the case group, some additional clinical information was also obtained from the patient records. This study was approved by University of Cruz Alta Research Ethics Committee (Number 54501216.4.0000. 5322).

\section{Clinical samples and human papillomavirus detection}

All women underwent cell sampling with buccal (case group) or cervical (control group) exfoliation using cytobrush and stored in a buffer solution (EDTA pH $8.00 .01 \mathrm{M}$, SDS $0.03 \mathrm{M}$ ) at $-20^{\circ} \mathrm{C}$ until analysis. DNA extraction and HPV detection/typing were performed as described in previous studies. ${ }^{10,11}$

\section{Single nucleotide polymorphism analysis}

A fragment of $199 \mathrm{bp}$ of the TP53gene, nesting rs1042522, was amplified by PCR using primers previously described, ${ }^{12}$ while a fragment of $267 \mathrm{bp}$ of the NQO1 gene, nesting rs1800566, was amplified by PCR using the following primers: forward (F 5'GGTAACGGCTAGGTAGAGGG - $3^{\prime}$ ) and reverse (R 5'- ATTTGAAT TCGGGCGTCTGC $-3^{\prime}$ ). The cycling conditions for both reactions were as follows: initial denaturation at $94^{\circ} \mathrm{C}$ for 5 minutes, 45 cycles of $94^{\circ} \mathrm{C}$ for 10 seconds, $55^{\circ} \mathrm{C}$ for 30 seconds and $72^{\circ} \mathrm{C}$ for 30 seconds. The SNPs rs 1042522 and rs 1800566 were evaluated by restriction digestion with BstUI and HinfI enzymes (Thermo Fisher Scientific, Dreieich, Germany), respectively. The results were analyzed by polyacrylamide gel electrophoresis stained with silver nitrate. SNP rs2305809 in RPS19gene was evaluated using a TaqMan ${ }^{\circledR}$ SNP genotyping assay C_3060197_1 (Applied Biosystems, Foster City, CA, USA). Allelic discrimination real-time PCR was performed on the StepOnePlus ${ }^{\mathrm{TM}}$ with the following cycling conditions: 10 minutes at $95^{\circ} \mathrm{C}$ followed by 45 cycles of 15 seconds at $95^{\circ} \mathrm{C}$ and 1 minute at $60^{\circ} \mathrm{C}$. Allelic discrimination was measured by end-point fluorescence using StepOne ${ }^{\mathrm{TM}}$ Software version 2.3 and TaqMan ${ }^{\circledR}$ Genotyping Software version 1.3 (Applied Biosystems, Waltham, MA, USA).

\section{Statistical analysis}

Data were analyzed using the Statistical Package for Social Sciences ver. 18.0 (PASW; IBM Co., Armonk, NY, USA). The 
Student $t$-test for independent samples was used to detect statistical differences between quantitative variables. Allele and genotypes frequencies were determined by direct counting and Hardy- Weinberg equilibrium was evaluated by chi-square test. The genetic models used were additive (genotypes), recessive (Arg/Arg + Arg/Pro vs. Pro/Pro for rs1042522, Pro/Pro + Pro/Ser vs. Ser/Ser for rs1800566, and C/C + C/T vs. T/T for rs2305809) and dominant (Arg/Pro + Pro/Pro vs. Arg/Arg for rs1042522, Pro/Ser + Ser/Ser vs. Pro/Pro for rs1800566, and C/T + T/T vs. C/C for rs2305809). Associations between qualitative variables and CC were evaluated by bivariate analysis (Pearson's chi-square test). The crude odds ratios (crudeOR) with 95\% CI were estimated in order to detect the association of the SNPs with CC. Logistic regression analysis was conducted to control possible interferences of covariates that presented $P$-values $\leq 0.10$ in the bivariate analysis of socio-demographic and behavioral variables. Therefore, the adjusted odds ratios ( ${ }_{\text {adjusted }} \mathrm{OR}$ ) with $95 \% \mathrm{CI}$ were estimated. Statistical power calculations of the sample were performed using the software Epi Info $^{\mathrm{TM}}$ version 7.1.5.2 considering minor allele frequencies (MAF) for rs1042522, rs1800566, and rs2305809 in control group. All $P$-values presented are two-tailed and those with values $<0.05$ were considered significant.

\section{RESULTS}

Socio-demographic and behavioral data in the sample studied are presented in Table 1. In the comparison of these characteristics, cases and controls did not present statistically significant differences, except for parity (94.3\% in cases vs. $55.5 \%$ in controls; $P<0.01)$, contraceptive oral use (17.9\% vs. $32.5 \%$; $P<$ $0.01)$, to have $\geq 2$ lifetime sexual partners (49.1\% vs. $62.0 \%$; $P=$ 0.02 ) and sexual debut at $\leq 18$ years-old (66.7\% vs. $48.2 \% ; P<$ $0.01)$. In the laboratory analysis, HPV detection was performed in all clinical cervical samples of the healthy women. HPV was detected in 78 (24.5\%; mean age: $43.4 \pm 12.3$ ) women. Sociodemographic and behavioral data were compared between HPV positive and HPV negative women and there was no significant difference in all characteristics (data not shown). All samples were used in the comparative analysis between cases and controls because the observed frequency of HPV positive women is expected in the whole women population of this geographic

Table 1. Bivariate analysis of socio-demographic and behavioral data of the case and control groups

\begin{tabular}{|c|c|c|c|}
\hline Variable & Case & Control & $P$-value \\
\hline Age $(y r)^{a}$ & $50.45 \pm 14.38$ & $48.12 \pm 14.38$ & 0.15 \\
\hline \multicolumn{4}{|l|}{ Educational level ${ }^{\mathrm{b}}$} \\
\hline Complete primary education or less & $72(68.6)$ & $188(69.1)$ & 0.92 \\
\hline Secondary or higher education & $33(31.4)$ & $84(30.9)$ & \\
\hline \multicolumn{4}{|c|}{ Total household income (in Brazilian minimum monthly wage) ${ }^{b}$} \\
\hline Household income $\geq 2$ minimum salary & $51(48.6)$ & $98(51.0)$ & 0.68 \\
\hline Household income $\leq 1$ minimum salary & $54(51.4)$ & $94(49.0)$ & \\
\hline \multicolumn{4}{|l|}{ Smoking ${ }^{\mathrm{b}}$} \\
\hline No & $81(77.1)$ & $169(85.8)$ & 0.06 \\
\hline Yes & $24(22.9)$ & $28(14.2)$ & \\
\hline \multicolumn{4}{|l|}{ Parity ${ }^{\mathrm{b}}$} \\
\hline No & $6(5.7)$ & $142(44.5)$ & $<0.01$ \\
\hline Yes & $100(94.3)$ & $177(55.5)$ & \\
\hline \multicolumn{4}{|l|}{ Contraceptive oral use ${ }^{\mathrm{b}}$} \\
\hline No & $87(82.1)$ & $217(65.9)$ & $<0.01$ \\
\hline Yes & $19(17.9)$ & $107(32.5)$ & \\
\hline \multicolumn{4}{|l|}{ Condom use in all sexual relations ${ }^{\mathrm{b}}$} \\
\hline No & $83(78.3)$ & $152(77.6)$ & 0.88 \\
\hline Yes & $23(21.7)$ & $44(22.4)$ & \\
\hline \multicolumn{4}{|l|}{ No. of lifetime sexual partners $\geq 2^{\mathrm{b}}$} \\
\hline No & $54(50.9)$ & $92(38.0)$ & 0.02 \\
\hline Yes & $52(49.1)$ & $150(62.0)$ & \\
\hline \multicolumn{4}{|l|}{ Sexual debut at $\leq 18$ years-old ${ }^{b}$} \\
\hline No & $35(33.3)$ & $99(51.8)$ & $<0.01$ \\
\hline Yes & $70(66.7)$ & $92(48.2)$ & \\
\hline
\end{tabular}

Values are presented as mean \pm SD or number (\%). ${ }^{a}$ Student $t$-test was used to evaluate possible differences of age between groups. ${ }^{b}$ Totals do not coincide due to the lack of data. 
region. $^{11}$

Allele frequencies of the SNPs rs1042522, rs1800566, and rs2305809 are shown in Table 2 . It is noteworthy that MAF were $28.9 \%$ of Pro allele (nucleotide G) for rs $1042522,25.3 \%$ of Ser allele (nucleotide T) for the rs 1800566 , and $49.8 \%$ of T allele/nucleotide for rs2305809. The allele frequencies did not show statistically significant differences between the groups evaluated. The frequencies observed in the population for these three SNPs are in Hardy-Weinberg equilibrium.

Genetic models analysis of the SNPs rs1042522, rs1800566, and rs2305809 are shown in Table 3. Additive, dominant and recessive models analysis for rs1042522 and rs1800566 SNPs did not present significant differences between CC cases and control group in bivariate and logistic regression analysis (Table 3). However, the recessive genetic model $(\mathrm{C} / \mathrm{C}+\mathrm{C} / \mathrm{T})$ for rs2305809 located in the upstream region of the RPS19gene was statistically more frequent in the control group (79.9\%) compared to the cases (69.8\%), being associated with CC protection in bivariate (crude $\mathrm{OR}=$ 0.58; $95 \% \mathrm{CI}: 0.35-0.95, P=0.03)$ and logistic regression analysis (adjusted $\mathrm{OR}=0.49 ; 95 \% \mathrm{CI}: 0.27-0.90, P=0.02$ ).

\section{DISCUSSION}

In the analysis of the patient's data, CC women presented a mean age of 50.5 years, consistent with the incidence peak of this disease in Brazil. ${ }^{2}$ MAF were evaluated for the three SNPs, demonstrating similar data to other women populations from Latin America (32\% for Pro in rs1042522, 33\% for Ser in rs 1800566 , $43 \%$ for T in rs2305809) and Europe (29\% for Pro in rs1042522, $21 \%$ for Ser in rs $1800566,47 \%$ for C in rs 2305809$).{ }^{13}$ The small differences between the MAF are probably related to the ethnic profile of the samples evaluated in these different populations.
In the comparative analysis between cases and controls, we detected an association between the recessive genetic model ( $C / C$ $+\mathrm{C} / \mathrm{T}$ ) in rs2305809 and protection for CC. Further, the presence of allele $\mathrm{T}$ demonstrated a trend of risk for $\mathrm{CC}$. The other SNPs studied were not associated with CC.

Our results suggest non-association between SNP rs1042522 in TP53gene in women with CC. These SNP had already been largely studied presenting conflicting data. Firstly, Pro allele was associated with HPV persistence and increased risk of cervical lesions in women from Costa Rica. ${ }^{14}$ On oppose, another study suggested that the persistent HPV types 16 and 18 infections were related to Arg/Arg genotype in patients with $\mathrm{CC} .{ }^{15}$ A meta-analysis review demonstrated that women with HPV and Arg allele had a significantly high risk for the appearance of cervical lesion. Arg allele was also associated with progression of the cervical lesion to cancer in the occurrence of persistent HPV infection. ${ }^{5}$

We also have not found an association between SNP rs 1800566 and CC. Studies associating rs1800566 in the NQO1 gene with CC are scarce. Ser/Ser genotype was demonstrated to be a risk factor for CC in Japanese women. ${ }^{16}$ On oppose, another study demonstrated an association between the Pro allele and CC in Caucasian women from the United States of America. ${ }^{6}$ However, it is noteworthy that the Ser allele of NQO1 gene is less common in the Caucasian population $(\fallingdotseq 0.25)$ compared with the Asian population $(\fallingdotseq 0.42) .{ }^{13}$

Finally, there are two previous reports demonstrating significant associations of the SNP rs2305809 in RPS19gene with $\mathrm{CC}$ and HPV infection. ${ }^{7.8}$ Both of them demonstrated $\mathrm{T}$ as the allele for protection to CC as well as to HPV infection in Central America and Nigeria women, respectively. ${ }^{7,8}$ The present study reported for the first time that the genotype TT and allele $\mathrm{T}$ in this SNP is associated with CC. According to this, we hypothesized

Table 2. Allelic frequencies of gene TP53 (rs1042522), NQO1 (rs1800566), RPS19 (rs2305809) in patients with cervical cancer (cases) and healthy women (controls)

\begin{tabular}{lcccc}
\hline \multicolumn{1}{c}{ Variable } & Case $^{\mathrm{a}}$ & Control $^{\mathrm{a}}$ & Total & $P_{\text {-value }}^{\mathrm{b}}$ \\
\hline TP53 (rs1042522) & & & & \\
Arg & $135(70.3)$ & $441(71.4)$ & $576(71.1)$ & 0.78 \\
Pro & $57(29.7)$ & $177(28.6)$ & & \\
NQO1 (rs1800566) & & & $565(28.9)$ & \\
Pro & $131(76.20)$ & $434(72.6)$ & $205(25.3)$ & 0.35 \\
Ser & $41(23.8)$ & $164(27.4)$ & & \\
RPS19 (rs2305809) & $103(48.6)$ & $364(55.3)$ & $467(57.7)$ & 0.09 \\
C & $109(51.4)$ & $294(44.7)$ & $403(49.8)$ & \\
T & & & \\
\hline
\end{tabular}

Value are presented as number (\%). ${ }^{\mathrm{a}}$ Genotyping results were obtained for the single nucleotide polymorphisms rs1048522 ( $\mathrm{n}=96$ cases and $\mathrm{n}=309$ controls), rs1800566 ( $\mathrm{n}=86$ and $\mathrm{n}=299$ controls), and rs2305809 ( $\mathrm{n}=106$ cases and $\mathrm{n}=329$ controls). ${ }^{\mathrm{b}}$ Pearson's chi-squared test. 
Table 3. Analysis of genotypes and alleles of gene TP53 (rs1042522), NQO1 (rs1800566), RPS19 (rs2305809) in patients with cervical cancer (cases) and healthy women (controls)

\begin{tabular}{|c|c|c|c|c|c|c|}
\hline Genetic model & Case $^{\mathrm{a}}$ & Control $^{\mathrm{a}}$ & crude $\mathrm{OR}(95 \% \mathrm{CI})$ & $P$-value & adjusted $\mathrm{OR}(95 \% \quad \mathrm{CI})^{\mathrm{b}}$ & $P$-value \\
\hline \multicolumn{7}{|l|}{ Additive } \\
\hline Arg/Arg & $47(49.0)$ & $161(52.1)$ & 1.00 & & 1.00 & \\
\hline Arg/Pro & $41 \quad(42.7)$ & $119(38.5)$ & $1.18(0.73-1.91)$ & 0.50 & $1.11(0.56-1.59)$ & 0.83 \\
\hline Pro/Pro & $8(8.3)$ & $29(9.4)$ & $0.94(0.40-2.20)$ & 0.89 & $0.94(0.36-2.43)$ & 0.90 \\
\hline \multicolumn{7}{|l|}{ Recessive $^{c}$} \\
\hline 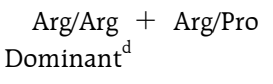 & $88(91.6)$ & $280(90.6)$ & $1.13(0.50-2.58)$ & 0.75 & $1.38(0.68-2.79)$ & 0.35 \\
\hline \multicolumn{7}{|l|}{ NQO1 (rs1800566) } \\
\hline \multicolumn{7}{|l|}{ Additive } \\
\hline Pro/Pro & $49(57.0)$ & $164(54.9)$ & 1.00 & & 1.00 & \\
\hline Pro/Ser & $33(38.4)$ & $106(35.4)$ & $1.04(0.63-1.73)$ & 0.87 & $1.05(0.61-1.81)$ & 0.84 \\
\hline Ser/Ser & $4(4.7)$ & $29(9.7)$ & $0.46(0.16-1.37)$ & 0.16 & $0.37(0.12-1.19)$ & 0.09 \\
\hline \multicolumn{7}{|l|}{ Recessive $^{c}$} \\
\hline $\begin{array}{l}\text { Pro/Pro } \\
\text { Dominant }^{\mathrm{d}}\end{array}$ & $82(95.3)$ & $270(90.3)$ & $2.20(0.75-6.44)$ & 0.15 & $1.39(0.75-2.58)$ & 0.30 \\
\hline $\begin{array}{l}\text { Pro/Ser }+ \text { Ser/Ser } \\
\text { RPS19 (rs2305809) }\end{array}$ & $37(43.0)$ & $135(45.1)$ & $0.92(0.56-1.49)$ & 0.73 & $0.75(0.44-1.26)$ & 0.28 \\
\hline \multicolumn{7}{|l|}{ Additive } \\
\hline $\mathrm{CC}$ & $29(27.4)$ & $101(30.7)$ & 1.00 & & 1.00 & \\
\hline $\mathrm{CT}$ & $45(42.5)$ & $162(49.2)$ & $0.96(0.57-1.64)$ & 0.90 & $0.64(0.38-1.35)$ & 0.49 \\
\hline $\mathrm{TT}$ & $32(30.2)$ & $66(20.1)$ & $1.68(0.93-3.04)$ & 0.08 & $1.82(0.91-3.61)$ & 0.09 \\
\hline \multicolumn{7}{|l|}{ Recessive $^{c}$} \\
\hline \multicolumn{6}{|l|}{ Dominant $^{\mathrm{d}}$} & $0.02 *$ \\
\hline $\mathrm{CT}+\mathrm{TT}$ & $77(72.6)$ & $228(69.3)$ & $1.17(0.72-1.91)$ & 0.51 & $1.07(0.61-1.89)$ & 0.80 \\
\hline
\end{tabular}

Value are presented as number (\%). ${ }^{\mathrm{a} G e n o t y p i n g ~ r e s u l t s ~ w e r e ~ o b t a i n e d ~ f o r ~ t h e ~ s i n g l e ~ n u c l e o t i d e ~ p o l y m o r p h i s m s ~ r s ~} 1048522$ (n $=96$ cases and $n=309$ controls), rs1800566 ( $n=86$ and $n=299$ controls), and rs2305809 ( $n=106$ cases and $n=329$ controls). ${ }^{b}$ Adjusted OR for parity, contraceptive oral use, age at first intercourse $\leq 18$, number of lifetime sexual partners $\geq 2$ and smoking in logistic regression analysis. ${ }^{*}$-values $<0.05$ were considered statistically significant. ${ }^{c}$ Recessive genetic model (Arg/Arg + Arg/Pro vs. Pro/Pro for rs1042522, Pro/Pro + Pro/Ser vs. Ser/Ser for rs1800566, and CC + CT vs. TT for rs2305809). ${ }^{\mathrm{d} D o m i n a n t}$ genetic model (Arg/Pro + Pro/Pro vs. Arg/Arg for rs1042522, Pro/Ser + Ser/Ser vs. Pro/Pro for rs 1800566 , and CT + TT vs. CC for rs2305809).

that the recessive genetic model $(\mathrm{C} / \mathrm{C}+\mathrm{C} / \mathrm{T})$ causes a protective effect to $\mathrm{CC}$ in the women population of this study. These conflicting data seem to be similar to those of SNP rs1042522 in TP53. More studies and meta-analysis reviews are necessary to define the real role of this SNP. Experimental evidence has shown that the ribosomal S19 protein (encoded by the RPS19gene) has immunosuppressive properties, being upregulated in human ovarian and breast cancer cells and released from apoptotic cancer cells. ${ }^{17}$ In this way, this protein interacts with the complementary C5a receptor 1 expressed on tumor-infiltrating myeloid-derived suppressor cells. This interaction contributes to neoplastic growth since it facilitates the attraction of these cells to the tumor. ${ }^{17}$ Reducing RPS19 in cancer cells or blocking the C5a receptor 1-RPS19 interaction decreased RPS19-mediated immunosuppression, delayed the development of tumors, and impaired tumor growth in a transgenic model of breast cancer. ${ }^{17}$ Therefore, this set of factors can be influenced by the SNP rs2305809, which hypothetically act by regulating the gene expression of RPS19 protein or even the splicing process, contributing in the complex and cumulative frame to $\mathrm{CC}$.

Other polymorphisms are located in non-coding and coding regions of the RPS19 gene and could be involved with the regulation processes in the expression of this gene. ${ }^{18}$ All of them should be evaluated for a better understanding of the relationship between RPS19 and CC. For example, the SNP investigated here (rs2305809) has a high linkage disequilibrium ${ }^{13}$ to the SNPs (rs4803512, rs6509002, rs58857981, rs7254214, rs7259596, and rs2075752) previously associated with DiamondBlackfan anemia. ${ }^{18}$

In conclusion, it was detected a protective association of the SNP rs2305809 in the recessive genetic model $(C / C+C / T)$ with $\mathrm{CC}$ in women from southern Brazil. Prospective cohort studies 
will be necessary to ascertain this association observed in the present case-control study as well as to define the relative risk of this SNP for CC. In addition, studies in populations with different genetic backgrounds will be needed to confirm our findings since genetic influences of CC are complex.

\section{ACKNOWLEDGMENTS}

The authors thank the staff of the Center of High Complexity in Oncology of the Ijuí, RS, and participants for their collaboration. We also thank the technicians of the Universidade de Cruz Alta (Cytopathology Laboratory), Universidade Luterana do Brasil (Molecular Diagnostics Laboratory) who performed technical support and Simbios Biotecnologia for the partial financial support. This work was also supported by Fundação de Amparo à Pesquisa do Estado do Rio Grande do Sul (FAPERGS; Grant 1265-2551/13-4) and by the Coordenação de Aperfeiçoamento de Pessoal de Nível Superior - Brasil (CAPES; Finance Code 001).

Financial resources to perform the laboratory analyses were obtained in the project "Study of human and viral genetic factors associated with the persistence of genital papillomavirus and progression to cervical cancer" submitted and approved in the FAPERGS/MS/CNPq/SESRS Notice n. 002/2013-Research Program for SUS: Shared health management PPSUS-2013/2015.

\section{CONFLICTS OF INTEREST}

No potential conflicts of interest were disclosed.

\section{REFERENCES}

1. International Agency for Research on Cancer. GLOBOCAN 2012: estimated cancer incidence, mortality and prevalence worldwide in 2012. http://globocan.iarc.fr/Default.aspx. Accessed July, 2018.

2. Instituto Nacional de Câncer José Alencar Gomes da Silva. Estimativa 2016: incidência de câncer no Brasil. http://www. inca.gov.br/bvscontrolecancer/publicacoes/edicao/Estimativa_ 2016.pdf. Acceessed July, 2018.

3. Georgieva S, Iordanov V, Sergieva S. Nature of cervical cancer and other HPV-associated cancers. J BUON 2009;14:391-8.

4. Wang SS, Bratti MC, Rodríguez AC, Herrero R, Burk RD, Porras C, et al. Common variants in immune and DNA repair genes and risk for human papillomavirus persistence and progression to cervical cancer. J Infect Dis 2009;199:20-30.

5. Habbous S, Pang V, Eng L, Xu W, Kurtz G, Liu FF, et al. p53 Arg72Pro polymorphism, HPV status and initiation, progression, and development of cervical cancer: a systematic review and meta-analysis. Clin Cancer Res 2012;18:6407-15.

6. Hu X, Zhang Z, Ma D, Huettner PC, Massad LS, Nguyen L, et al. TP53, MDM2, NQO1 and susceptibility to cervical cancer. Cancer Epidemiol Biomarkers Prev 2010;19:755-61.

7. Safaeian M, Hildesheim A, Gonzalez P, Yu K, Porras C, Li Q, et al. Single nucleotide polymorphisms in the PRDX3 and RPS19 and risk of HPV persistence and cervical precancer/cancer. PLoS One 2012; 7:e33619.

8. Famooto A, Almujtaba M, Dareng E, Akarolo-Anthony S, Ogbonna C, Offiong R, et al. RPS19 and TYMS SNPs and prevalent high risk human papilloma virus infection in Nigerian women. PLoS One 2013;8:e66930.

9. da Rocha Boeira T, Wolf JM, Coser J, Grivicich I, Simon D, Lunge VR. Polymorphisms in genes related to cervical cancer in a Brazilian population: a case-control study [published onlined ahead of print March 15, 2018]. Pathol Oncol Res 2018. doi: $10.1007 / \mathrm{s} 12253-018-0414-8$.

10. Coser J, da Rocha Boeira T, Simon D, Kazantzi Fonseca AS, Ikuta $\mathrm{N}$, Lunge VR. Prevalence and genotypic diversity of cervical human papillomavirus infection among women from an urban center in Brazil. Genet Mol Res 2013;12:4276-85.

11. Coser J, Boeira Tda R, Wolf JM, Cerbaro K, Simon D, Lunge VR. Cervical human papillomavirus infection and persistence: a clinic-based study in the countryside from South Brazil. Braz J Infect Dis 2016;20:61-8.

12. Fan R, Wu MT, Miller D, Wain JC, Kelsey KT, Wiencke JK, et al. The p53 Codon 72 polymorphism and lung cancer risk. Cancer Epidemiol Biomarkers Prev 2000;9:1037-42.

13. Ensembl Genome Browser. 1000 genomes project phase 3 allele frequencies. http://www.ensembl.org/index.html. Accessed July, 2018.

14. Koshiol J, Hildesheim A, Gonzalez P, Bratti MC, Porras C, Schiffman M, et al. Common genetic variation in TP53 and risk of human papillomavirus persistence and progression to CIN3/ cancer revisited. Cancer Epidemiol Biomarkers Prev 2009;18: 1631-7.

15. Piña-Sánchez P, Hernández-Hernández DM, Taja-Chayeb L, Cerda-Flores RM, González-Herrera AL, Rodea-Avila C, et al. Polymorphism in exon 4 of TP53 gene associated to HPV 16 and 18 in Mexican women with cervical cancer. Med Oncol 2011; 28:1507-13.

16. Niwa Y, Hirose K, Nakanishi T, Nawa A, Kuzuya K, Tajima K, et al. Association of the $\mathrm{NAD}(\mathrm{P}) \mathrm{H}$ : quinone oxidoreductase C609T polymorphism and the risk of cervical cancer in Japanese subjects. Gynecol Oncol 2005:96:423-9.

17. Markiewski MM, Vadrevu SK, Sharma SK, Chintala NK, Ghouse S, Cho JH, et al. The ribosomal protein S19 suppresses antitumor immune responses via the complement C5a receptor 1 . J Immunol 2017;198:2989-99.

18. Martinez Barrio A, Eriksson O, Badhai J, Fröjmark AS, Bongcam-Rudloff E, Dahl N, et al. Targeted resequencing and analysis of the Diamond-Blackfan anemia disease locus RPS19. PLoS One 2009:4:e6172. 